\title{
Evaluation of trabecular bone patterns on dental radiographic images: influence of cortical bone.
}

\author{
Yves Amouriq*ab $^{\text {ab }}$ Pierre Evenou ${ }^{\mathrm{a}}$, Aurore Arlicot ${ }^{\mathrm{a}}$, Nicolas Normand ${ }^{\mathrm{a}}$, Pierre Layrolle ${ }^{\mathrm{c}}$, Pierre \\ Weiss $^{\mathrm{c}}$, Jeanpierre Guedon ${ }^{\mathrm{a}}$. \\ ${ }^{a}$ IRCCyN/IVC - UMR CNRS 6597- École Polytechnique University of Nantes. La Chantrerie, BP \\ 50609, 44306 Nantes - France \\ ${ }^{\mathrm{b}}$ ERT 2004, UMR_S 791- Odontology dpt University of Nantes. 1 Place A. Ricordeau F44042 \\ Nantes - France \\ ${ }^{\mathrm{c}}$ LIOAD, INSERM, UMR S791 - Odontology dpt University of Nantes, 1 place A Ricordeau \\ F44042 Nantes - France
}

\begin{abstract}
For some authors trabecular bone is highly visible in intraoral radiographs. For other authors, the observed intrabony trabecular pattern is a representation of only the endosteal surface of cortical bone, not of intermedullary striae. The purpose of this preliminary study was to investigate the true anatomical structures that are visible in routine dental radiographs and classically denoted trabecular bone. This is a major point for bone texture analysis on radiographs. Computed radiography (CR) images of dog mandible section in molar region were compared with simulations calculated from high-resolution micro-CT volumes. Calculated simulations were obtained using the Mojette Transform. By digitally editing the $\mathrm{CT}$ volume, the simulations were separated into trabecular and cortical components into a region of interest. Different images were compared and correlated, some bone micro-architecture parameters calculated. A high correlation was found between computed radiographs and calculated simulations from micro-CT. The Mojette transform was successful to obtain high quality images. Cortical bone did not contribute to change in a major way simulated images. These first results imply that intrabony trabecular pattern observed on radiographs can not only be a representation of the cortical bone endosteal surface and that trabecular bone is highly visible in intraoral radiographs.
\end{abstract}

Keywords: bone microarchitecture, mandible, trabecular, cortical, bone analysis, Mojette transform

\section{INTRODUCTION}

Radiography is a noninvasive and/or nondestructive technique which can provide structural information about bone. Bone texture analysis ${ }^{1,2}$ on a radiograph is supposed to give informations about trabecular bone microarchitecture. But, what do we really see on a bone radiograph? On a dental X-ray image, maxillar and mandible bone is visible around the teeth. The purpose of this study is to investigate the true anatomical structures that are visible in routine dental radiographs and classically denoted trabecular bone. For some authors real trabecular bone is highly visible in intraoral radiographs ${ }^{3,4}$. For other authors, the intrabony trabecular pattern observed is a representation of the endosteal surface of cortical bone, not of intermedullary striae ${ }^{5,6,7,8,9}$. Our ultimate goal is then to characterize the correlation between the radiograph and the micro CT scan data to label each pixel or voxel either as trabecular or cortical bone.

*yves.amouriq@univ-nantes.fr, phone+336087664 45

7626 - 57 V. 3 (p.1 of 10) / Color: No / Format: A4 / Date: 2010-01-18 04:27:19 AM

SPIE USE: DB Check, Prod Check, Notes: 


\section{MATERIALS AND METHODS}

\subsection{Digital radiographs}

A dog (Beagle) mandible section in molar regions with one tooth was used as model experiment. Digital radiographs (DR) were performed using classical dental Kodak RVG system (digital radiography system, Kodak, Rochester, NewYork, USA, figure 1) and D3A medical systems radiograph (digital radiography system, D3A, Orléans, France, figure 2). A Region Of Interest (ROI) including trabecular and cortical bone was determined between tooth roots. We used also radiographs performed by micro Computed Tomography $(\mu \mathrm{CT})$.

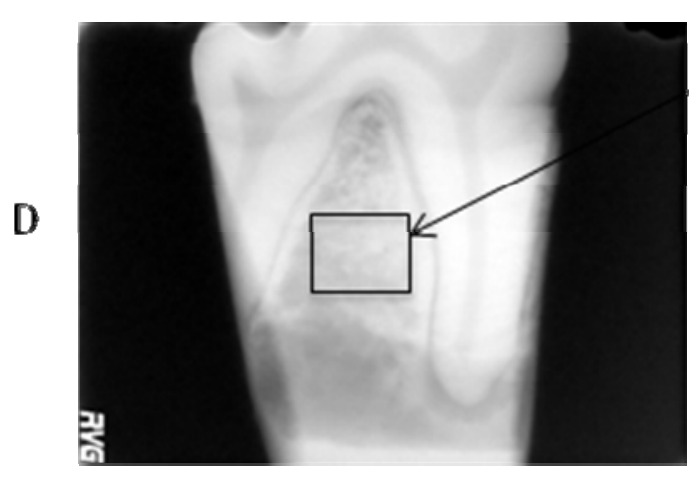

Figure 1: Digital dental radiograph Kodak

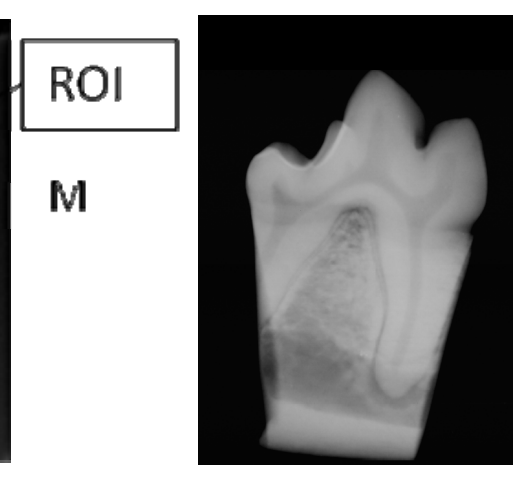

Figure 2 : D3A medical system radiograph

\subsection{Micro Computed-Tomography}

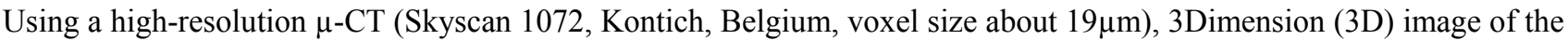
ROI was created (figure 3 ) from the same sample.

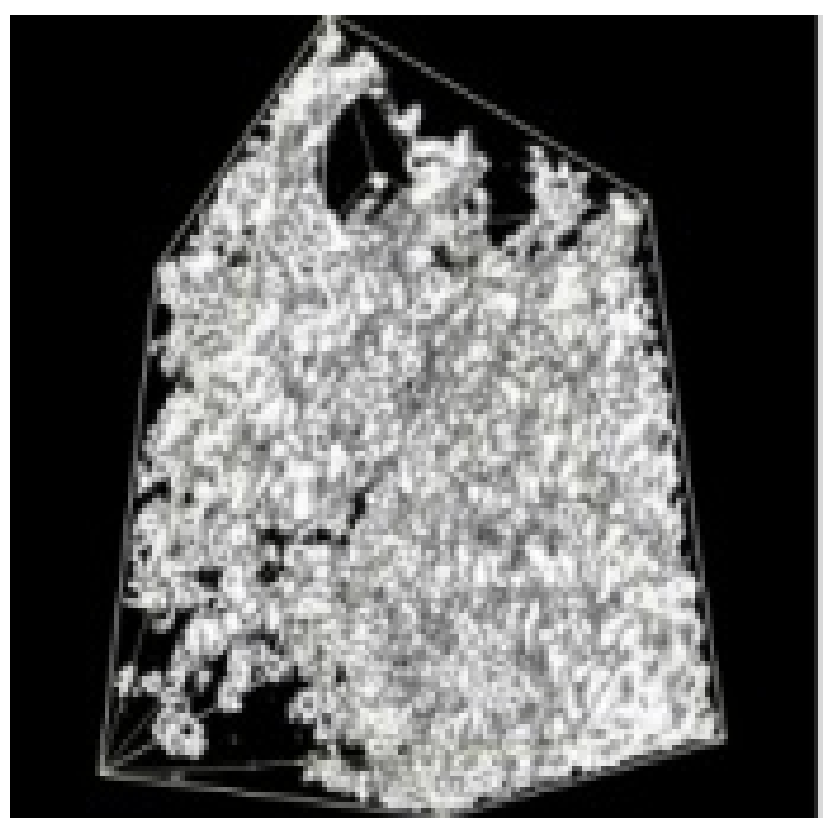

Figure 3 : ROI 3D reconstruction $(\mu \mathrm{CT})$ 
From about 275 radiographs, $\mu$-CT created 1007 slices from 3D volume. The ROI contains about 137 slices. Computed radiography $(\mathrm{CR})$ images of the mandible section were compared with simulations calculated from $\mu$-CT.

\subsection{Calculated simulated radiographs}

Calculated simulations were obtained using the Mojette Transform ${ }^{10}$ by Digital Radiograph Reprojection (DRR) from the 3D ROI as depicted in figure 4.

When rq is non zero, the generic parallel Mojette projector obeys to:

$\left.\operatorname{proj}\left(\mathrm{b}_{1} ; \mathrm{b}_{2}, \mathrm{p}, \mathrm{q}, \mathrm{r}\right)=\mathrm{M}_{\delta} \mathrm{f}(\mathrm{k}, \mathrm{l}, \mathrm{m})=\sum_{\mathrm{k}} \sum_{1} \sum_{\mathrm{m}} \mathrm{f}(\mathrm{k}, \mathrm{l}, \mathrm{m}) \Delta\left(\left(\mathrm{b}_{\mathrm{b}_{2}}\right)-\mathrm{P}_{32}\left(\begin{array}{l}\mathrm{k} \\ 1 \\ \mathrm{~m}\end{array}\right)\right)\right)$

where $\mathrm{P}_{32}$ is a $3 \times 2$ projection matrix of direction $(\mathrm{p}, \mathrm{q}, \mathrm{r}),\left(\mathrm{b}_{1}, \mathrm{~b}_{2}\right)$ is the digital position of a bin onto the radiograph and $(\mathrm{k}, \mathrm{l}, \mathrm{m})$ the voxel position. In this problem, we manage the experimental situation to reduce the (p,q,r) projection angle to equal $(1,0,0)$ which leads to the simplified equation:

$\operatorname{proj}\left(\mathrm{b}_{1} ; \mathrm{b}_{2}, \mathrm{p}, \mathrm{q}, \mathrm{r}\right)=\mathrm{M}_{\delta} \mathrm{f}(\mathrm{k}, 1, \mathrm{~m})=\sum_{\mathrm{k}} \mathrm{f}\left(\mathrm{k}, \mathrm{b}_{1} ; \mathrm{b}_{2}\right)$

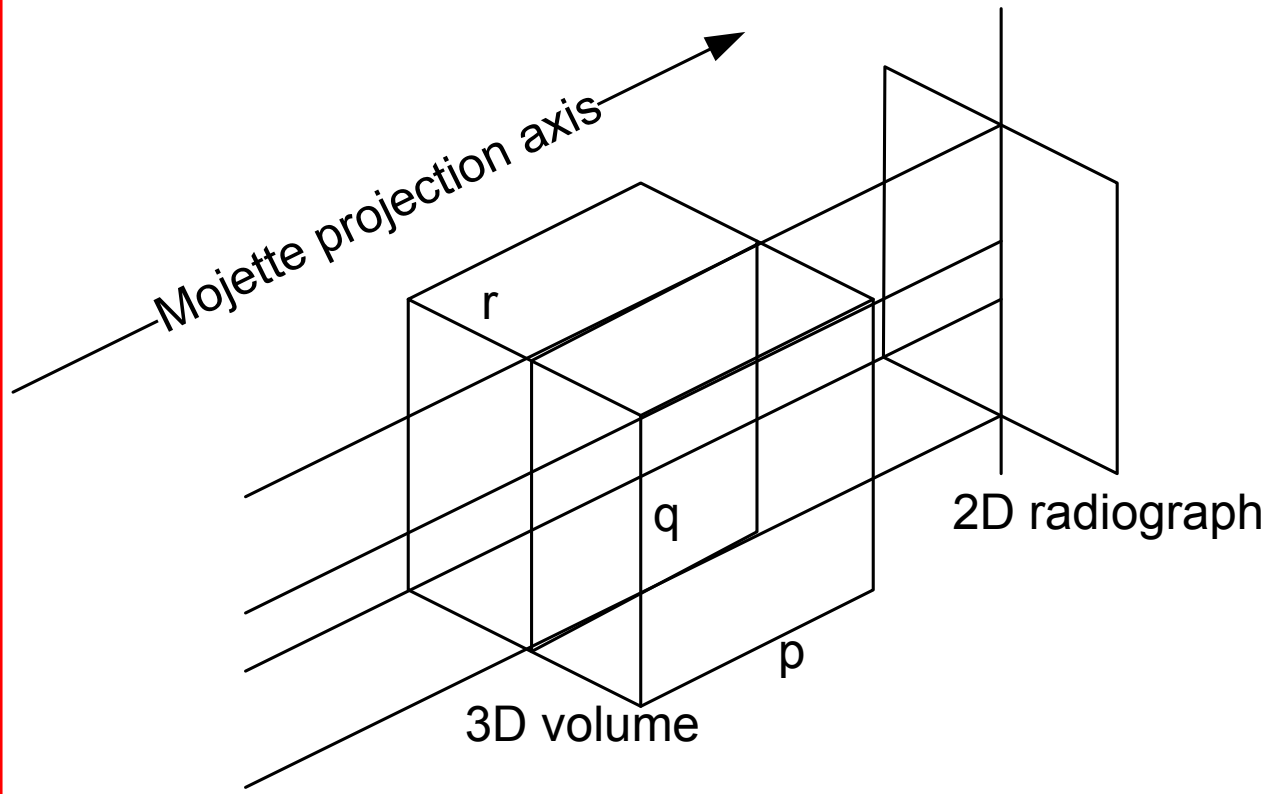

Figure 4 Mojette Transform and DRR

By digitally editing the $\mathrm{CT}$ volumes, the simulations were separated into trabecular and cortical components into a 3D ROI which was also reprojected. The separation into trabecular and cortical components on the 137 slices was obtained using two ways: line sections at the junction cortical-trabecular bone and individualized section (human drawing on several images, computed drawing on others images using interpolation as results in figure 5). 


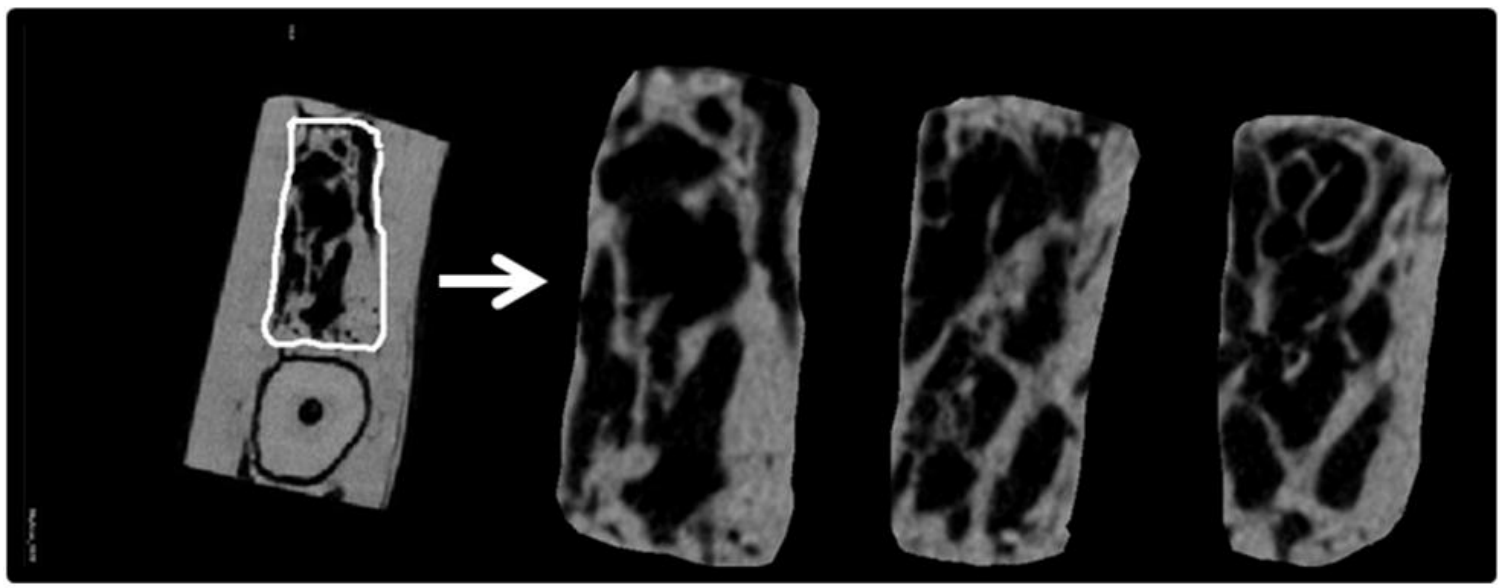

Figure 5 Individualized section of trabecular bone on several slices (human drawing and interpolation)

The Mojette parallel projector was used to obtain several images from portions of the 3D ROI (the rest of the 3D volume is set to zero) :

- Full bone (cortical and trabecular bone)

with different positions of line sections (several translations about $300 \mu \mathrm{m}$ from the two initial line sections at position 0 , see figure 6):

- Trabecular bone (with different thickness ranging from position $0,+600 \mu \mathrm{m},+1200 \mu \mathrm{m},+1800 \mu \mathrm{m},-$ $600 \mu \mathrm{m},-1200 \mu \mathrm{m})$

- Cortical bone (with different thickness ranging from position $0,+600 \mu \mathrm{m},+1200 \mu \mathrm{m},-600 \mu \mathrm{m},-1200 \mu \mathrm{m}$,$1800 \mu \mathrm{m})$

- Jonction zone between cortical and trabecular bone (addition of the 2 junctions zone with different thickness : ranging from 600 to $1200 \mu \mathrm{m}$ and different positions)

- Cortical and trabecular bone but without the 2 junction zones cortical-trabecular (with different thickness of the junction zone cortical-trabecular 600 to $1200 \mu \mathrm{m}$ )

with individualized section (figure 7):

- Trabecular bone

- Cortical bone

The Mojette projection created about 35 different images parallel rays - DRR.

\subsection{Correlation between radiographs et simulated images obtained using the Mojette Transform}

To assess the abilities of the Mojette Transform in performing calculated images similar to radiographs, radiograph of the ROI was compared to full bone (cortical and trabecular bone) image of the ROI computed by the Mojette Transform. Subtraction on images and linear correlation were used. In the same way, we compared radiograph of the ROI and the addition of two images of the ROI simulated by Mojette Transform : image of trabecular bone and image of cortical bone. 


\section{TRABECULAR BONE}

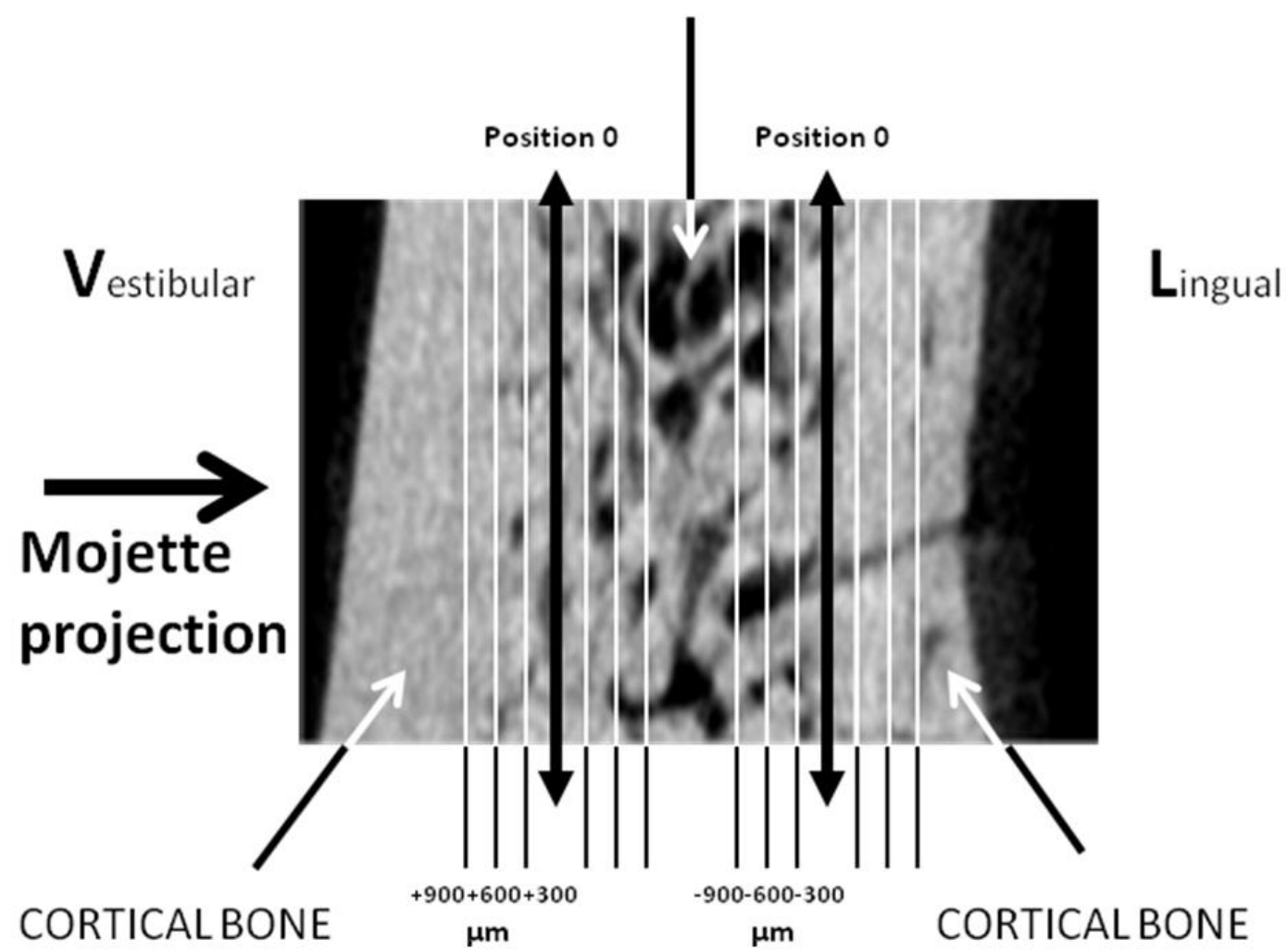

Figure 6 Separation between cortical and trabecular bone in the ROI (line section)

TRABECULAR BONE

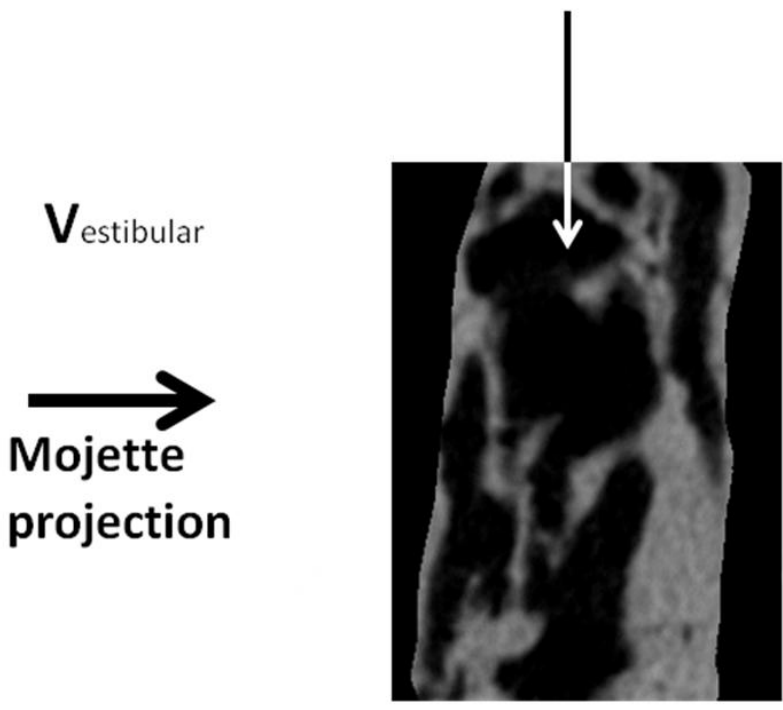

Lingual

Figure 7 Separation between cortical and trabecular bone in the ROI (individualized section) 


\subsection{Bone microarchitecture parameters}

Bone microarchitecture parameters on the trabecular zone of the ROI were calculated using $\mu \mathrm{CT}$ software (CT AN, Skyscan 1072, Kontich, Belgium).

\subsection{Evaluation of trabecular bone patterns on dental radiographic images}

We used comparison between images to evaluate trabecular bone patterns and determinate the influence of cortical bone. All simulated images were compared to full bone (cortical and trabecular bone) image (similar to a dental radiograph). Linear correlation coefficient was performed.

\section{RESULTS}

\subsection{Calculated simulated radiographs using the Mojette Transform}

About 35 different images, radiographic calculated simulations, were obtained using the Mojette Transform on the ROI (figure 8).

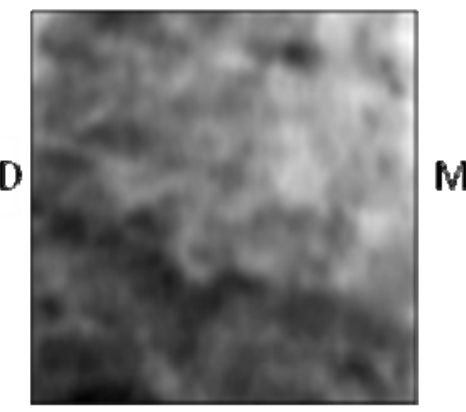

BONE (cortical + trabecular)

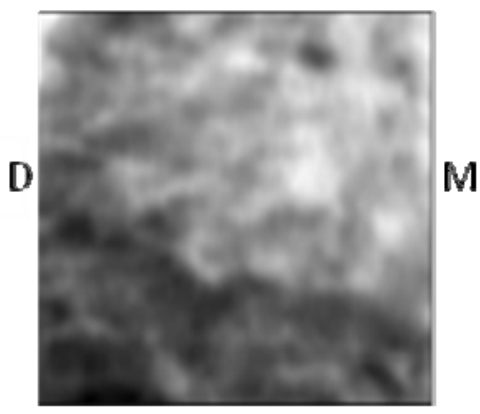

TRABECULAR BONE

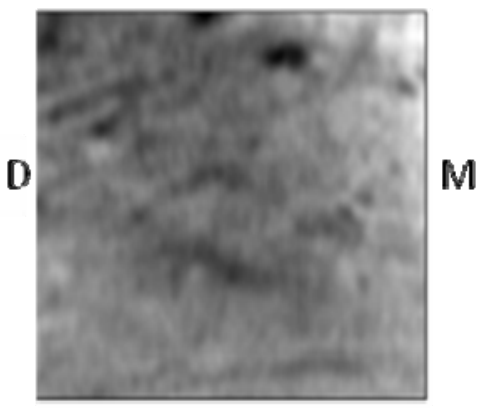

CORTICAL BONE

Figure 8: Three examples of calculated simulation image of the ROI : Bone (full projection trabecular and cortical bone), Trabecular bone alone and Cortical bone alone (line section at position 0 ). D and $\mathrm{M}$ : distal and mesial orientation.

No difference could be pointed out between radiograph of the ROI and full bone (cortical and trabecular bone) DRR of the ROI: Subtraction on images gave a perfect black image (all pixels to 0) and linear correlation was 1. Comparison between radiograph of the ROI and the addition of two images of the ROI simulated by Mojette Transform (trabecular bone and image of cortical bone image section at position 0 ) gave exactly the same results. The Mojette transform was successfull to obtain high quality reprojected images similar to radiographs.

From a visual evaluation, images of trabecular bone and images of full bone without the 2 junction zones trabecularcortical always appeared to be nearly similar to ROI radiograph. Cortical bone images or junction bone images did not appear to be similar to ROI radiograph.

\subsection{Bone microarchitecture parameters}

Table 1 presents the bone microarchitecture parameters of the trabecular zone of the ROI. 
Table 1 Bone microarchitecture parameters from $\mu \mathrm{CT}$.

\begin{tabular}{l|l|ll} 
Tissue volume & TV & 57,19979 & $\mathrm{~mm}^{\wedge} 3$ \\
\hline Bone volume & BV & 39,43129 & $\mathrm{~mm}^{\wedge} 3$ \\
\hline Percent bone volume & BV/TV & 68,93607 & $\mathrm{~mm}^{\wedge} 2$ \\
\hline Tissue surface & TS & 114,16948 & $\mathrm{~mm}^{\wedge} 2$ \\
\hline Bone surface & BS & 229,24168 & $\mathrm{~mm}^{\wedge} 2$ \\
\hline Intersection surface & i.S & 93,15771 & $1 / \mathrm{mm}$ \\
\hline Bone surface / volume ratio & BS/BV & 5,8137 & $1 / \mathrm{mm}$ \\
\hline Bone surface density & BS/TV & 4,00774 & $1 / \mathrm{mm}$ \\
\hline Trabecular pattern factor & Tb.Pf & $-1,2197$ & $\mathrm{~mm}$ \\
\hline Centroid (x) & Crd.X & 8,17915 & $\mathrm{~mm}$ \\
\hline Centroid (y) & Crd.Y & 11,16222 & $\mathrm{~mm}$ \\
\hline Centroid (z) & Crd.Z & 10,49072 & $1 / \mathrm{mm}$ \\
\hline Structure model index & SMI & $-0,3307$ & $\mathrm{~mm}$ \\
\hline Trabecular thickness & Tb.Th & 0,65245 & \\
\hline Trabecular number & Tb.N & 1,0565 & \\
\hline Trabecular separation & Tb.Sp & 0,5035 &
\end{tabular}

\subsection{Linear correlation with the full bone image}

Table 2 summarizes the correlation results. According to its border positions, the trabecular bone images have a linear correlation result between 0.84-0.97.

The cortical bone images have a linear correlation result between $0.53-0.87$.

The junction zone trabecular-cortical bone have a linear correlation result between 0.61-0.86.

The full bone (without the 2 junction zones trabecular-cortical bone) images have a linear correlation result between 0.84-0.99.

\section{DISCUSSION}

A high correlation was found between radiographs and calculated simulations from micro-CT (linear correlation=1, perfect black issued from images subtraction). The used of Mojette Transform was successful and allowed us to compare the images obtained by parallel rays DRR to determinate the influence of cortical bone.

We used Beagle dog mandible section because this bone is very similar to human mandible bone ${ }^{11}$. The trabecular part of the ROI presents a high density bone with $68 \%$ bone (volume), a low trabecular separation $(0.5 \mathrm{~mm})$ and an important trabecular thickness $(0.65 \mathrm{~mm})$. These calculated bone microarchitecture parameters in the ROI could be found in some human mandible.

According to the visual evaluation, we obtained a better linear correlation coefficient with trabecular bone images than with cortical bone images (typical 0.97 versus 0.75 with section line method or 0.88 versus 0.74 with individualized section method) or than with trabecular-cortical junction zone (including cortical bone endosteal surface) images (typical 0.97 versus 0.75 ). On full bone images, the suppression of the 2 junction zones did not decrease highly the linear correlation coefficient (typical 0.96). In all cases, results with the different line sections showed that the linear correlation decreases when trabecular bone decreases. In the same way, in the steps of trabecular bone suppression, linear correlation decreases slowly on trabecular bone images according to the poor linear correlation of junction zone. 
Table 2 Linear correlation values between full bone ROI image and simulated images

\begin{tabular}{|c|c|}
\hline TRABECULAR BONE & \\
\hline $\begin{array}{l}\text { Trabecular bone position } 0 \\
\mathbf{0 . 9 6 9 9 8}\end{array}$ & $\begin{array}{l}\text { Trabecular bone }+600 \mu \mathrm{m} \\
\mathbf{0 . 9 7 0 5 2}\end{array}$ \\
\hline $\begin{array}{l}\text { Trabecular bone }+1200 \mu \mathrm{m} \\
\mathbf{0 . 9 7 1 5 1}\end{array}$ & $\begin{array}{l}\text { Trabecular bone }+1800 \mu \mathrm{m} \\
\mathbf{0 . 9 6 0 2 1}\end{array}$ \\
\hline $\begin{array}{l}\text { Trabecular bone }-600 \mu \mathrm{m} \\
\text { 0.93015 }\end{array}$ & $\begin{array}{l}\text { Trabecular bone }-1200 \mu \mathrm{m} \\
\mathbf{0 . 8 4 8 2 4}\end{array}$ \\
\hline \multicolumn{2}{|l|}{ CORTICAL BONE } \\
\hline $\begin{array}{l}\text { Cortical bone position } 0 \\
\mathbf{0 . 7 4 7 0 2}\end{array}$ & $\begin{array}{l}\text { Cortical bone }+600 \mu \mathrm{m} \\
\mathbf{0 . 7 4 7 3 7}\end{array}$ \\
\hline $\begin{array}{l}\text { Cortical bone }+1200 \mu \mathrm{m} \\
\mathbf{0 . 8 7 5 1 6}\end{array}$ & $\begin{array}{l}\text { Cortical bone }-600 \mu \mathrm{m} \\
\mathbf{0 . 7 4 6 0 8}\end{array}$ \\
\hline $\begin{array}{l}\text { Cortical bone }-1200 \mu \mathrm{m} \\
\mathbf{0 . 7 3 6 6 3}\end{array}$ & $\begin{array}{l}\text { Cortical bone }-1800 \mu \mathrm{m} \\
\mathbf{0 . 5 3 9 4 4}\end{array}$ \\
\hline \multicolumn{2}{|l|}{$\begin{array}{l}\text { JUNCTION ZONE CORTICAL- } \\
\text { TRABECULAR }\end{array}$} \\
\hline $\begin{array}{l}\text { Junction zone } 1200 \mu \mathrm{m} * 2(-600 \mu \mathrm{m}+600 \mu \mathrm{m}) \\
\mathbf{0 . 7 4 7 5 2}\end{array}$ & $\begin{array}{l}\text { Junction zone } 600 \mu \mathrm{m} * 2(-600 \mu \mathrm{m}-1200 \mu \mathrm{m}) \\
\mathbf{0 . 7 5 2 4 6}\end{array}$ \\
\hline $\begin{array}{l}\text { Junction zone } 1200 \mu \mathrm{m} * 2(-1200 \mu \mathrm{m} 0 \mu \mathrm{m}) \\
\mathbf{0 . 7 5 0 2 4}\end{array}$ & $\begin{array}{l}\text { Junction zone } 600 \mu \mathrm{m} * 2(0 \mu \mathrm{m}+600 \mu \mathrm{m}) \\
\mathbf{0 . 7 4 5 9 8}\end{array}$ \\
\hline $\begin{array}{l}\text { Junction zone } 1200 \mu \mathrm{m} * 2(0 \mu \mathrm{m}+1200 \mu \mathrm{m}) \\
\mathbf{0 . 8 6 0 5 0}\end{array}$ & $\begin{array}{l}\text { Junction zone } 600 \mu \mathrm{m} * 2(0 \mu \mathrm{m}-600 \mu \mathrm{m}) \\
\text { 0.74681 }\end{array}$ \\
\hline $\begin{array}{l}\text { Junction zone } 600 \mu \mathrm{m} * 2(+600 \mu \mathrm{m}+1200 \mu \mathrm{m}) \\
\text { 0.61450 }\end{array}$ & $\begin{array}{l}\text { Full bone without the } 2 \text { junction zones }(+600 \mu \mathrm{m}+1200 \mu \mathrm{m}) \\
\mathbf{0 . 8 4 3 4 8}\end{array}$ \\
\hline \multicolumn{2}{|l|}{ FULL BONE WITHOUT JUNCTION ZONES } \\
\hline $\begin{array}{l}\text { Full bone without the } 2 \text { junction zones }(-600 \mu \mathrm{m}+600 \mu \mathrm{m}) \\
\mathbf{0 . 9 5 9 0 5}\end{array}$ & $\begin{array}{l}\text { Full bone without the } 2 \text { junction zones }(-600 \mu \mathrm{m}-1200 \mu \mathrm{m}) \\
\mathbf{0 . 9 9 6 4 3}\end{array}$ \\
\hline $\begin{array}{l}\text { Full bone without the } 2 \text { junction zones }(-1200 \mu \mathrm{m} 0 \mu \mathrm{m}) \\
\mathbf{0 . 9 9 3 5 8}\end{array}$ & $\begin{array}{l}\text { Full bone without the } 2 \text { junction zones }(0 \mu \mathrm{m}+600 \mu \mathrm{m}) \\
\mathbf{0 . 9 6 3 8 5}\end{array}$ \\
\hline $\begin{array}{l}\text { Full bone without the } 2 \text { junction zones }(0 \mu \mathrm{m}+1200 \mu \mathrm{m}) \\
\mathbf{0 . 8 8 3 4 5}\end{array}$ & $\begin{array}{l}\text { Full bone without the } 2 \text { junction zones }(0 \mu \mathrm{m}-600 \mu \mathrm{m}) \\
\mathbf{0 . 9 9 8 4 2}\end{array}$ \\
\hline \multicolumn{2}{|l|}{ INDIVIDUALIZED SECTION } \\
\hline $\begin{array}{l}\text { Trabecular bone (individualized section) } \\
\mathbf{0 , 8 7 8 9 4}\end{array}$ & $\begin{array}{l}\text { Cortical bone (individualized section) } \\
\mathbf{0 , 7 4 4 2 8}\end{array}$ \\
\hline
\end{tabular}

Cortical bone or junction zone between trabecular and cortical bone did not contribute to change in a major way simulated images. These results of this preliminary study may imply that:

-intrabony trabecular pattern observed on radiographs can not only be a representation of the cortical bone endosteal surface,

-cortical bone do not really change the image on the radiograph,

- trabecular bone is highly visible in intraoral radiographs.

It has been shown that the analysis of two dimensional (2D) bone X-ray images is a good way for quantifying alterations in the three dimensional bone micro-architecture. Nonetheless, the 2D actual measurement is not a direct assessment of the $3 \mathrm{D}$ bone properties ${ }^{12}$.

These results allows for completing the analysis between the 2D radiographs that can be obtained in a routine manner from patients and the 3D underlying bone structure. 


\section{CONCLUSION}

The Mojette transform was successfully employed to obtain high quality reprojected images (parallel rays DRR) and could be used in 2D and 3D medical images for bone texture analysis. Links between 2D radiographs and 3D micro CT for bone characterization have already been studied. However, the digital tools used here and the high correlations obtained allows for optimistic future characterization on alive bone through only radiographs. According to this work, cortical bone or cortical bone endosteal surface are poorly visible in intraoral radiographs. Intermedullary striae and trabecular bone are highly visible and permit efficient texture analysis. The knowledge of bone anatomical structures which are visible in digital reprojected radiographs is useful for a future better $3 \mathrm{D}$ bone analysis.

\section{ACKNOWLEGEMENTS}

The authors thank Mr Paul Pilet for technical assistance in $\mu \mathrm{CT}$ scanning, Dr Borhane Fellah and Pr J-M. Bouler for their help in this work.

\section{REFERENCES}

[1] Guggenbuhl, P., Bodic, F., Hamel, L., Baslé, M.F. and Chappard , D., "Texture analysis of X-ray radiographs of iliac bone is correlated with bone micro-CT,". Osteoporos Int. 17(3), 447-454 (2006).

[2] Materka, A. and Strzelecki, M., "Texture Analysis Methods - A Review," Technical University of Lodz, Institute of Electronics, COST B11 report, Brussels (1998).

[3] Couture, R.A., Whiting, B.R., Hildebolt, C.F and Dixon, D.A., "Visibility of trabecular structures in oral radiographs," Oral Surg Oral Med Oral Pathol Oral Radiol Endod. 96(6), 764-771 (2003).

[4] Colosi, D., Potluri, A., Islam, S., Geha, H. and Lurie A., "Brief communication: Bone trabeculae are visible on periapical images,” Oral Surg Oral Med Oral Pathol Oral Radiol Endod. 96(6), 772-773 (2003).

[5] Ramadan, A. B., E. and Mitchell, D.F., “A Roentgenographic study of experimental bone destruction,” Oral Surg Oral Med Oral Path Oral Radiol Endod 15, 934-943 (1962).

[6] Parfitt, G.J., "An investigation of the normal variations in alveolar bone trabeculation," Oral Surg Oral Med Oral Path Oral Radiol Endod. 15, 1453-1463 (1962).

[7] Bender, I.B., "Factors influencing the radiographic appearance of bony lesions," J Endod. 8, 161-70(1982).

[8] Cavalcanti, M.G., Ruprecht, A., Johnson, W.T., Southard, T.E. and Jakobsen, J., "The contribution of trabecular bone to the visibility of the lamina dura: an in vitro radiographic study," Oral Surg Oral Med Oral Pathol Oral Radiol Endod.

93, 118-122 (2002).

[9] Jett, S., Shrout, M.K., Mailhot, J.M, Potter, B.J. and Borke, J.L., "An evaluation of the origin of trabecular bone patterns using visual and digital image analysis," Oral Surg Oral Med Oral Pathol Oral Radiol Endod. 98(5), 598-604 (2004). 
[10] Guédon, J., [The Mojette transform, theory and applications], edited by Jeanpierre Guédon, ISTE-WILEY Publishers, London \& New-York (2009).

[11] Bodic, F., Amouriq, Y., Gauthier, O., Gayet-Delacroix, M., Bouler, J.M., Daculsi, G. and Hamel, L., “Computed tomography assessment of alveolar filling with an injectable bone substitute," J Mater Sci Mater Med 13(10), 953-958 (2002).

[12] Jennane, R., Harba, R., Lemineur, G., Bretteil, S., Estrade, A., Benhamou, C., L., "Estimation of the 3D selfsimilarity parameter of trabecular bone from its 2D projection," Medical Image Analysis 11, 91-98 (2007). 